\title{
"A Gente Fica Doente Também": Percepção do Cuidador Familiar sobre o seu Adoecimento
}

\author{
"We Get Sick Too": Family Caregivers' Perception on their \\ Sickening
}

\author{
Neli Machado de Souza Ahnerth1, Denise Martins Dourado2, Neuzilan, \\ Medeiros Gonzaga 33 , Josiane Alves Rolim44, Eraldo Carlos Batista ${ }^{5}$
}

\begin{abstract}
Resumo
O objetivo com este estudo foi compreender a percepção de 20 cuidadores sobre o processo de seu adoecimento quando em cuidado de um familiar em sofrimento mental. A pesquisa foi realizada por meio de uma abordagem qualitativa, do tipo descritiva, e o instrumento utilizado para a coleta de dados foi a entrevista semiestruturada. As informações foram analisadas seguindo as orientações da Análise de Conteúdo e interpretadas sob a perspectiva sóciohistórica. Os depoimentos mostraram que a percepção do cuidador sobre o seu adoecimento está atrelada à falta de apoio da família no cuidado e à abdicação da vida social e profissional após assumir a responsabilidade de cuidar do familiar em tratamento. O cuidador compreende, ainda, o cuidado como predestinação ou obrigação a ser cumprida. Evidencia-se a importância de uma relação colaborativa entre os serviços de saúde mental e a família como estratégia de apoio ao cuidador principal a fim de prevenir o seu adoecimento.
\end{abstract}

Palavras-chave: Cuidador familiar. Sofrimento mental. Saúde mental.

\begin{abstract}
The objective of this study is to understand the perception of 20 caregivers about their own process of becoming ill when taking care of a family member in mental distress. The study was conducted through a qualitative approach of the descriptive type, and for the data collection we used a semi structured interview. The information was analyzed following the guidelines of Content Analysis and interpreted from the socio-historical perspective. The testimonies showed that the caregivers' perception of their illness is linked to the family's lack of support in the care and their abdication of their social and professional life after taking on the responsibility of caring for the family member under treatment. Caregivers also understand care as predestination or obligation to be fulfilled. The importance of a
\end{abstract}

\footnotetext{
${ }^{1}$ Faculdade de Rolim de Moura, Rondônia, Brasil. E-mail: neli01ahnerth@hotmail.com.

${ }^{2}$ Faculdade de Rolim de Moura, Rondônia, Brasil. E-mail: denise.dourado.2010@hotmail.com.

${ }^{3}$ Faculdade de Rolim de Moura, Rondônia, Brasil. E-mail: lane_cliffe@hotmail.com.

${ }^{4}$ Faculdade de Rolim de Moura, Rondônia, Brasil. E-mail: josiane_rolim20@hotmail.com.

${ }^{5}$ Fundação Universidade Federal de Rondônia, Rondônia, Brasil. E-mail: eraldo.cb@hotmail.com.
} 
collaborative relationship between mental health services and families as a strategy to support the primary caregiver in order to prevent their own illness is evidenced.

Keywords: Family caregiver. Mental distress. Mental health. 


\section{Introdução}

O cuidar é definido como comportamentos e ações que envolvem conhecimento, valores, habilidades e atitudes, com a finalidade de beneficiar o indivíduo no processo de manter ou melhorar a condição humana no processo de viver e morrer. O cuidado está na constituição do ser humano, pelo envolvimento emocional implicado nele, e envolve atitudes de desvelo, solicitude e atenção ao outro, assim como preocupação e inquietação (Boff, 2014). Dessa maneira, fazem parte das necessidades básicas para a sobrevivência do ser humano: o cuidar de si próprio, o cuidar do outro e o ser cuidado (Oliveira, Cirilo \& Costa, 2013).

No âmbito social da saúde, o cuidado é uma ciência praticada em instituições por profissionais especializados, como enfermeiros, técnicos de enfermagem, entre outros. No contexto familiar, o cuidado pode ser realizado de duas formas: por um cuidador formal, contratado pela família para auxiliar um membro enfermo, ou por uma pessoa da família, que comumente fica responsável pelos cuidados diretos, como medicação, alimentação, acompanhamento regular às consultas médicas, fornecimento de suporte social e financeiro (Kebbe Rôse, Fiorati \& Carretta, 2014).

No campo da saúde mental, o cuidado informal ganhou relevância a partir da promulgação da Reforma Psiquiátrica, uma vez que, com as mudanças de paradigmas no atendimento à pessoa em sofrimento mental, em vez da doença, a pessoa passou a ser o centro da atenção. Nesse novo modelo de assistência em saúde mental, diferentes ações e atores foram incluídos, com o objetivo de superar a ênfase na perspectiva individual, que alicerça o modelo biomédico e hospitalocêntrico (Coelho, Velôso \& Barros, 2017). Essa assistência passou a ser realizada por uma rede de serviços psicossociais, com tratamentos clínicos para os indivíduos, eliminando as internações, para que não exista mais a exclusão social. Assim, a família passou a desempenhar novas tarefas referentes ao cuidado com o membro em sofrimento mental, que antes era função do Estado (Almeida, 2015; Costa, Jorge, Coutinho, Costa \& Holanda, 2016).

Reflete-se que se, por um lado, a Reforma Psiquiátrica, como movimento de caráter antimanicomial, gerou grande impacto na sociedade, remetendo a mudanças técnicoadministrativas, culturais e outras ligadas às pessoas em sofrimento mental, sobretudo no auxílio ao seu tratamento e no processo de desmitificação da loucura na comunidade (Batista, Ferreira \& Batista, 2017), por outro, a Reforma, em razão da desinstitucionalização, tem gerado questionamentos acerca da responsabilização da família pelo cuidado do familiar em sofrimento mental (Goulart, Silva \& Silva, 2015).

Compreendida algumas vezes como um movimento de mera desospitalização, sem, no entanto, garantir as condições necessárias de ressocialização e reabilitação, a Reforma Psiquiátrica causou fortes impactos sobre a família, pelo fato de ser o primeiro grupo em que o indivíduo se encontra. É na família que acontece o embate com a realidade cotidiana do cuidado ao familiar em sofrimento mental, pois ela é responsabilizada por acolher e cuidar desse indivíduo (Oliveira et al., 2013; Batista, Silva, Ferreira \& Batista, 2018).

O retorno do familiar em sofrimento mental para casa sem a devida orientação e suporte acarretou à família desestabilização em 
sua organização (Vicente et al., 2013). Essa dimensão pode se constituir algo novo para esses familiares, uma vez que deveriam se distanciar do membro em sofrimento mental, mas atualmente são requisitados a participar do seu cuidado (Covelo \& Badaró-Moreira, 2015). Para Gomes e Santos (2016), esse contexto de turbulência social instaurou um movimento paradoxal, em que, de um lado, a família assume o papel de centralidade nas políticas sociais, inclusive na saúde mental, e, por outro, ela sofre os efeitos da falta de responsabilidade crescente do Estado quanto a essas políticas, o que agravou especialmente os contextos familiares mais vulneráveis.

Nem todos os membros da família têm uma boa estrutura econômica e emocional para enfrentar as reações do membro em sofrimento mental. E, nesse novo cenário, quase sempre a família indica um membro seu como cuidador principal, tornando-o responsável pelos provimentos indispensáveis ao cotidiano do familiar em sofrimento mental (Batista, 2015). Com isso, o cuidador passa a vivenciar situações que afetam direta e indiretamente a sua subjetividade e o levam a sofrer não somente com o familiar em sofrimento mental, mas também com as relações conflituosas geradas no próprio contexto familiar. Como consequência da sua nova função, a qualidade de vida do cuidador é reduzida em virtude da sobrecarga física e psicológica e da abdicação, pelo menos em parte, da sua vida social e profissional (Batista, 2015; Oliveira et al., 2013; Sant'Ana, Pereira, Borenstein \& Silva, 2011).

O cuidado cotidiano de um familiar em sofrimento mental engloba um processo de atenção especial ao cuidador, não se restringindo às orientações, ao acompanhamento, à medicação, à alimentação e aos cuidados de higiene; acrescentam-se a isso a convivência com comportamentos não convencionais, como falar sozinho, humor instável e isolamento social, do familiar em sofrimento mental. Essa nova conjuntura exige do cuidador habilidades para lidar com as pressões do cotidiano e para manter seu bem-estar físico e psíquico, o que envolve uma série de questões pessoais, sociais, emocionais e financeiras relacionadas à convivência com o adoecimento mental (Cardoso \& Galera, 2011; Nascimento et al., 2016; Souza, Caldas, Pinto \& Soares, 2011).

Outro fator desestabilizador na vida de quem assume a função de cuidador principal diz respeito aos conflitos intrafamiliares que surgem com a chegada de um membro em sofrimento mental. A falta de informação e compreensão sobre a doença tende a ocasionar uma divisão familiar, fragilizando a relação entre o cuidador e o ente em sofrimento mental (Batista, 2015). Esses conflitos podem gerar cansaço, estresse, baixa autoestima, impaciência e sentimentos de agonia e tristeza no cuidador (Vicente et al., 2013) e, consequentemente, ele apresentará sinais e sintomas, como fadiga, isolamento social, ansiedade, entre outros sintomas físicos (Delalibera, Presa, Barbosa \& Leal, 2015; Nascimento et al., 2016; Olegário et al., 2012).

A falta de suporte social, como o não reconhecimento dos familiares por ter assumido esse papel, e a falta de apoio nos cuidados ao paciente, além do distanciamento dos amigos, têm implicações negativas na vida do cuidador, uma vez que o isolamento e a ruptura dos vínculos sociais aumentam a vulnerabilidade dos sujeitos ao adoecimento e ao sofrimento (Fonseca, Penna \& Soares, 2008). Nesse sentido, conviver em tempo integral com o paciente e não ter tempo disponível para atividades individuais 
pode ser um agravante para a saúde do cuidador; nos casos em que a doença tem um longo curso, o alerta é ainda mais intensificado (Nascimento et al., 2016).

Todos esses aspectos negativos envolvidos no processo de cuidar de um familiar em sofrimento mental têm sido objetos de vários estudos e são comumente denominados de sobrecarga familiar, gerada em decorrência dessa função (Cardoso \& Galera, 2011; Cardoso, Galera \& Vieira. 2012; Cardoso, Vieira, Ricci \& Mazza, 2012; Fonseca et al., 2008; Kebbe et al., 2014; Olegário et al., 2012; Sant'Ana et al., 2011; Coelho et al., 2017).

A expressão sobrecarga familiar refere-se a uma experiência de "fardo a carregar", a qual é vivida por familiares de pessoas em sofrimento mental, ou seja, ela é usada para descrever os aspectos negativos associados ao cuidado de indivíduos doentes (Cardoso et al., 2012). Baseiase na perturbação causada pela presença do sofrimento mental que o doente apresenta no ambiente familiar, pois compreende aspectos econômicos, práticos e emocionais, afetando o cuidador responsável pelos cuidados necessários e exigidos por ele (Sant'Ana et al., 2011).

Essa sobrecarga divide-se em duas vertentes: sobrecarga objetiva, relacionada às consequências negativas da presença de uma pessoa em sofrimento mental na família, como acúmulo de tarefas, aumento de custos financeiros, limitação das atividades cotidianas, fragilização dos relacionamentos entre os familiares, entre outros; e sobrecarga subjetiva, que diz respeito à percepção pessoal do familiar sobre a experiência de conviver com o doente, seus sentimentos quanto à responsabilidade e preocupações que envolvem o cuidado a sua saúde (Cardoso et al., 2012).
Nesse sentido, como afirmam Coelho et al. (2017), os profissionais devem estar atentos aos fatores que causam essa sobrecarga e à qualidade dos relacionamentos estabelecidos entre as pessoas em sofrimento psíquico e suas famílias, pois assumir a responsabilidade de cuidador sem poder contar com o auxílio de outros familiares pode gerar um grande esgotamento, comprometendo a sua vida social, profissional e financeira. Normalmente esse cuidador abdica de sua vida para cuidar do familiar, não dispondo de tempo nem de espaço para outros convívios sociais (Kebbe et al., 2014; Sant'Ana et al., 2011).

Tendo em vista as questões problematizadoras anteriormente expostas e a importância de pesquisas sobre cuidadores em saúde mental que contemplam vários ângulos do fenômeno (Coelho, et al., 2017), neste buscou-se analisar essa temática a partir de uma concepção sócio-histórica do sujeito em questão. Essa perspectiva fundamenta-se no marxismo e adota o materialismo histórico e dialético como filosofia, teoria e método. Nesse pensamento, o homem é concebido como ser ativo, social e histórico; a sociedade, como produção histórica dos homens por meio do trabalho; e a história, como movimento contraditório constante do fazer humano (Bock, 2015). Dessa forma, a linguagem como constituidora do sujeito (Vygotsky, 2008) ocupa um lugar central nessa perspectiva - compreendida como instrumento fundamental no processo de mediação das relações sociais, por meio da qual o homem se individualiza, humaniza-se, apreende e materializa o mundo das significações que é construído no processo social e histórico (Aguiar, 2015). A linguagem é um recurso essencial para o desenvolvimento deste estudo, pois a fala, 
construída e expressa pelo cuidador na sua relação com a pessoa em sofrimento mental, corresponde à maneira como ele é capaz de compreender como se processa o seu adoecimento em virtude da atividade do cuidado.

Dessa maneira, neste estudo teve-se como questão norteadora a seguinte indagação: como o cuidador de uma pessoa em sofrimento mental percebe o seu adoecimento? Para responder a tal questionamento o objetivo foi compreender a percepção do cuidador familiar de um membro em sofrimento mental sobre o processo de adoecimento decorrente da atividade de cuidar.

\section{Material e método}

Trata-se de uma pesquisa de abordagem qualitativa, do tipo descritiva, orientada pela teoria sócio-histórica. Os estudos qualitativos, com o olhar dessa perspectiva, valorizam os aspectos descritivos e as percepções pessoais, focalizam o particular como instância da totalidade social e buscam compreender os sujeitos envolvidos e, por seu intermédio, compreender também o contexto (Freitas, 2002). Nesse enfoque, acredita-se que o indivíduo, apesar de ser único, contém a totalidade social e a expressa nas suas ações, pensamentos e sentimentos, e o processo apreendido a partir de um sujeito pode revelar algo constitutivo de outros sujeitos que vivem em condição semelhante (Aguiar, 2015). Nas palavras de Vygotsky (2004), o conhecimento do singular, ou seja, do indivíduo, é a chave de toda a Psicologia Social, e ele deve ser considerado um microcosmo, um tipo, um exemplo ou modelo da sociedade.

Participaram da pesquisa 20 cuidadores, que acompanhavam um membro da família em sofrimento mental, usuários do Centro de Atenção Psicossocial (Caps) de um município do interior do estado de Rondônia. Como critérios de inclusão, o participante da pesquisa deveria ser o principal cuidador, independentemente do grau de parentesco, e ser o responsável por auxiliar o usuário nas suas atividades cotidianas. Não participaram da pesquisa cuidadores com idades inferiores a 18 anos e aqueles que, por incapacidade emocional e/ou psicológica, não aderiram ao convite.

A coleta de dados foi realizada no período de dezembro de 2015 a fevereiro de 2016, mediante entrevistas gravadas pelos pesquisadores. De acordo com Freitas (2002), a entrevista, na pesquisa qualitativa de cunho sóciohistórico, não se reduz a uma troca de perguntas previamente preparadas e de respostas, mas é concebida como uma produção de linguagem, portanto, dialógica, em que os sentidos são criados na interlocução entre pesquisador e entrevistado. Nesse sentido, foi utilizado um roteiro de questões abertas que possibilitasse apreender falas reveladoras da construção histórica de cada cuidador.

Para iniciar o processo que culminou neste artigo, primeiramente foi realizada uma reunião com o coordenador e equipe de profissionais do Caps, na qual foram explicitados os objetivos do estudo; em seguida, foi obtida a colaboração dos profissionais e solicitado o fornecimento de dados dos prontuários presentes na instituição, a fim de se identificarem os usuários em tratamento psiquiátrico que tinham como cuidador principal um familiar; por fim foram verificadas datas e horários de agendamentos. Os participantes identificados foram abordados na instituição e convidados a 
participar da pesquisa. A coleta de dados foi realizada de forma individual em uma sala do Caps, após a apresentação dos objetivos e da leitura e assinatura do Termo de Consentimento Livre e Esclarecido (TCLE).

Após a coleta das informações, estas foram transcritas e o conteúdo foi analisado com base nos princípios teóricos da Análise de Conteúdo de Bardin (2011) e interpretado a partir da perspectiva sócio-histórica. De acordo com o enfoque histórico e social, considerando as falas/expressões do sujeito, visa-se à construção de um conhecimento que desvele a realidade pesquisada (Aguiar, 2015). A técnica de Análise de Conteúdo se constituiu das seguintes etapas: leitura das entrevistas; definição das unidades de registro e das unidades de significação; agrupamento em quatro categorias temáticas e descrição; e discussão das categorias (Bardin, 2011). Assim, o material coletado foi organizado a partir dos elementos textuais, buscando identificar as características singulares das falas dos entrevistados para permitir melhor compreensão sobre a realidade dos cuidadores e dos profissionais participantes da pesquisa.

No contexto da presente pesquisa, ratificando a adoção dos procedimentos pertinentes à importância do respeito à ética na pesquisa previstos na Resolução no 466/2012 do Conselho Nacional de Saúde (CNS), observou-se: a garantia do esclarecimento sobre a metodologia no início e durante o processo de coleta dos dados; a liberdade do sujeito de se recusar a participar ou de retirar seu consentimento a qualquer momento (por intermédio da formalização do TCLE); e a garantia de sigilo dos dados obtidos nas entrevistas. O projeto de pesquisa foi submetido à avaliação da Comissão de Ética e Pesquisa (CEP) da Faculdade de Rolim de Moura (Farol) e recebeu o parecer favorável $n^{\circ}$ 1.201.684 e CAAE no 47439015.2.0000.5605.

\section{Resultados e discussão}

\section{Caracterização dos participantes}

O estudo foi realizado com 20 cuidadores de um membro familiar em sofrimento mental, na faixa etária entre 18 e 81 anos, sendo cinco do sexo masculino e 15 do sexo feminino. Quanto ao grau de parentesco, seis eram mães, um pai, seis filhas, um filho, um irmão, uma avó, três cônjuges e um cunhado. Em relação ao estado civil, 12 declaram-se casados, três solteiros e cinco divorciados. A maioria afirmou ter estudado apenas até o nível fundamental, e 13 não tinham uma ocupação formal, apenas exerciam a atividade de cuidado do familiar. Seis participantes declararam ter renda familiar de dois salários mínimos, três afirmaram receber mais de dois salários mínimos mensais, oito apenas um salário mínimo e três menos de um salário mínimo, como demonstrado na Tabela 1. Quanto ao principal diagnóstico do familiar em tratamento, a esquizofrenia foi relatada pela maioria, seguida do diagnóstico de depressão. 
Tabela 1. Variáveis sociodemográficas

\begin{tabular}{|c|c|c|}
\hline Variável & Descrição & $\mathbf{N}^{\mathbf{o}}$ \\
\hline \multirow[t]{3}{*}{ Sexo } & Feminino & 15 \\
\hline & Masculino & 5 \\
\hline & Total & 20 \\
\hline \multirow[t]{5}{*}{ Idade } & $18-25$ & 3 \\
\hline & $26-40$ & 7 \\
\hline & $41-60$ & 5 \\
\hline & $>60$ & 5 \\
\hline & Total & 20 \\
\hline \multirow[t]{4}{*}{ Estado civil } & Solteiro & 3 \\
\hline & Casado/União estável & 12 \\
\hline & Divorciado/Separado & 5 \\
\hline & Total & 20 \\
\hline \multirow[t]{5}{*}{ Renda familiar } & > 2 salários mínimos & 3 \\
\hline & 2 salários mínimos & 6 \\
\hline & 1 salário mínimo & 8 \\
\hline & $<1$ salário mínimo & 3 \\
\hline & Total & 20 \\
\hline \multirow[t]{9}{*}{ Grau de parentesco } & Mãe & 6 \\
\hline & Pai & 1 \\
\hline & Filhas & 6 \\
\hline & Filhos & 1 \\
\hline & Irmão & 1 \\
\hline & Avó & 1 \\
\hline & Cônjuges & 3 \\
\hline & Cunhado & 1 \\
\hline & Total & 20 \\
\hline
\end{tabular}

Fonte: Elaborada pelos autores.

$\mathrm{Na}$ análise dos depoimentos dos cuidadores participantes no estudo, buscou-se desfragmentar e extrair como eles percebem o processo do seu adoecimento no decorrer do exercício do cuidado. $O$ tratamento das entrevistas resultou em quatro categorias: a) percepção do adoecimento pelo cuidador; b) ausência de apoio familiar; c) o cuidado como predestinação e obrigação do cuidador; e d) abdicação da vida social e profissional em prol do cuidado. 


\section{Percepçãodo adoecimento pelo cuidador}

A análise temática dos núcleos de significação identificados nos depoimentos permitiu observar que a sobrecarga que recai sobre o cuidador familiar em relação à atividade de cuidado do membro em sofrimento mental envolve fatores emocionais, econômicos, relacionais, físicos e psicológicos. Desde a leitura flutuante das entrevistas, o que chamou a atenção, a partir da fala dos entrevistados, foi a preocupação com o seu possível adoecimento em virtude da atividade de cuidar do familiar em sofrimento mental, a qual pode ser exemplificada por meio de alguns trechos das falas dos entrevistados. As respostas a seguir foram geradas a partir da seguinte pergunta: como você percebe a sua saúde depois que se tornou cuidador principal do seu familiar?

Eu sofro muito; preciso tratar de mim também, se não eu vou adoecer. Já estou adoecendo. (C14, irmã)

Para mim acho que complicou mais, porque tive que deixar minha vida pra cuidar dela, aí quando ela foi fazer tratamento que caiu a ficha que eu tinha parado de cuidar de mim. Aí, sei lá, acho que eu adoeci. (C3, filha)

Está muito difícil; tem horas que acho que não vou aguentar. Já chorei muito, mas Deus vai me ajudar a suportar essa cruz. (C13, mãe)

Se eu me preocupar muito, a gente fica doente também. (C8, esposo)

É nesse contexto de sobrecarga que o entrevistado ressalta o seu descaso com a própria saúde em virtude do tempo dispensado ao familiar. É notável que o envolvimento com a pessoa em sofrimento mental é tão intenso que o cuidador não percebe que está adoecendo. Segundo Cabral e Nunes (2015), a negligência de cuidado com a própria saúde pode ter ligação, mesmo que inconsciente, com algum interesse próprio em obter ganhos para si, ser reconhecido ou recompensado. $\mathrm{O}$ fato de não perceber o próprio adoecimento pode ser visto nos depoimentos dos participantes a seguir.

Um desgaste físico e mental muito grande acompanhado de uma grande preocupação. Eu percebo que tenho que cuidar da minha própria saúde, pois lidar com esse problema todo dia pode gerar uma depressão. (C12, esposa)

Quando o médico disse que ele não tinha mais jeito, eu fiquei muito triste, fiquei doente, chorava muito, sentia muita dor de cabeça e não conseguia trabalhar direito. (C11, filho)

O sentimento de impotência e tristeza ao receber o diagnóstico de algum tipo de transtorno mental do familiar parece bastante comum na fala dos cuidadores. Esses sentimentos podem estar relacionados ao desconhecimento dos sintomas do transtorno pela família. A sensação de não saber o que o familiar tem é acompanhada pelo sentimento de angústia, o que mobiliza no cuidador processos pessoais de busca por um modelo explicativo sobre a origem da doença e mesmo de busca por ajuda e/ou tratamento (Batista, 2015; Delgado, 2014).

As limitações do entendimento do cuidador sobre o sofrimento mental do familiar podem estar associadas a fatores sociais, culturais, religiosos e econômicos que tendem a dificultar a 
compreensão. Para Souza et al. (2011), a falta de manejo com os cuidados necessários ao familiar em sofrimento mental está atrelada principalmente à falta de conhecimento diante do processo de adoecimento. Isso se deve ao fato de que a inserção da família não foi efetivada completamente nos serviços substitutivos, e só se dá importância a esse aspecto quando se foca em ações para o usuário (Covelo \& Badaró-Moreira, 2015). Nesse sentido, a equipe de saúde tem papel fundamental na explicação e orientação ao cuidador familiar quanto ao cuidado a partir do diagnóstico e no seu engajamento numa rede de apoio que o oriente quanto aos cuidados com sua própria saúde (Oliveira et al., 2013; Nascimento et al., 2016; Coelho et al., 2017). Desse modo, o cuidador não somente estará bem preparado para essa nova função como também em alerta sobre possíveis sinais e sintomas de seu adoecimento resultante da atividade do cuidado (Fonseca et al., 2008). Nos depoimentos a seguir, registram-se percepções a esse respeito, quando alguns cuidadores notaram mudanças em sua saúde.

Olha, eu comecei com essa dor de estômago, desmaio, muita dor de cabeça, ansiedade. Não conseguia dormir, e assim agita muito a cabeça. Parece que o miolo [cérebro] ferve. Aí a pressão começou a alterar também. Daí comecei a tomar remédio pra pressão alta. (C18, mãe)

Depois que entrei na família, minha saúde deu uma caída [ficou frágill, pois fico preocupado. Eles doentes me deixam doente. (C5, cunhado)

Fiquei mais nervoso, estressado e comecei a ter problema de pressão alta. (C9, esposo)
O surgimento desses sintomas indica a necessidade de cuidado específico do próprio cuidador, em consequência do seu estado de saúde (Gomes, Silva \& Batista, 2018). O fato de conviver com um membro em sofrimento mental faz com que esses cuidadores fiquem sempre apreensivos, ansiosos e preocupados. Assim, a equipe de saúde deve estar atenta durante a assistência, observando de forma clara e objetiva os sinais e sintomas manifestos em outros membros da família, sobretudo no cuidador principal.

\section{Ausência de apoio familiar}

A falta da rede de apoio familiar no cuidado do membro em sofrimento mental foi relatada pela maioria dos participantes. Essa situação reflete uma realidade da sociedade atual, na qual a retração das redes sociais e familiares acontece cada vez mais (Fonseca et al., 2008). Os depoimentos dessa categoria analítica emergiram das respostas à seguinte indagação: como você avalia a colaboração da sua família no cuidado?

Bem estressante. Você não tem mais, como se diz, eu fico preocupada, com medo de ficar igual a ela, porque sobrecarrega só eu. Porque no meio de cinco filhos, os filhos deixam só pra mim. Então, eu acho, assim, que se a família colaborasse, acho que facilitaria bem mais o doente mental, porque ele se sente uma pessoa desprezada. Se a própria família o despreza, que a própria família não tem aquele negócio de ter aquele carinho de estar buscando. Se a família desse $\mathrm{o}$ suporte não sobrecarregaria $\mathrm{o}$ 
cuidador, e a saúde da outra pessoa seria melhor, mas aí sobrecarrega só um. (C19, filha)

Nessa fala, fica bem evidente que o fato de ser a única cuidadora da mãe tem provocado nessa cuidadora certa indignação e sentimentos negativos em decorrência da sobrecarga sofrida pela ausência de apoio da família. Covelo e Badaró-Moreira (2015) afirmam que, após o diagnóstico de um familiar em sofrimento mental, uma das consequências é o afastamento de amigos e parentes do convívio familiar. Esse distanciamento contribui diretamente tanto para a sobrecarga objetiva, pois acarreta o acúmulo de tarefas, quanto para a subjetiva, relacionada ao fato de o cuidador se sentir sozinho. Dessa forma, ao assumir com exclusividade o cuidado de um doente da família, o cuidador principal tende a sofrer um desgaste físico e emocional muito grande. Muitas vezes, o afastamento dos familiares pode ser explicado pela incompreensão da doença mental. Para Sant'Ana et al. (2011), as pessoas da família que não convivem diariamente com um membro em sofrimento mental mostram certo receio de se aproximar para ajudar nos cuidados, pois desconhecem e não compreendem a doença e suas manifestações ou, muitas vezes, nem se interessam em saber como podem ajudar, apenas se afastam desse familiar. Nos trechos a seguir, os informantes relatam como percebem o adoecimento resultante dessa sobrecarga.

Eu sinto minha saúde assim [debilitada], que a partir do momento que a gente pega um compromisso pra cuidar a gente vai cuidando, vai cuidando, vai se esforçando cada vez mais, a gente vai se enfraquecendo cada vez mais, o organismo vai enfraquecendo, ele não resiste, aí fica fraco. (C18, mãe)

Quando eu comecei a cuidar dela, eu não tinha problema nenhum; aí depois que ela piorou que eu adoeci [ficou em silêncio e começou a chorar]. (C18, mãe) A minha saúde, eu notei, não sei se foi por causa da idade, mas ela "caiu" [fragilizou]. (C2, mãe)

Mudou. Alterou sim, sinto ansiedade, nervoso, cansaço [...] muita coisa alterou, perturbação na cabeça, antes eu não tinha nada e depois que eu comecei a cuidar dela [esposa] tudo começou. (C9, esposo)

Existe uma coincidência bastante geral nas falas dos entrevistados, no que se refere à manifestação de sintomas psicológicos e emocionais após assumirem a nova função. Tais acontecimentos corroboram as considerações de Gomes e Santos (2016) ao explanarem que o contexto familiar de adoecimento mental já traz em si inúmeras tensões e conflitos, e quando essa realidade se mescla a uma conjuntura marcada por adversidades, conforme os relatos, tende a se tornar ainda mais complexa. A sobrecarga emocional apresentada nos depoimentos anteriormente expostos se refere à percepção pessoal sobre a experiência de conviver com o familiar em sofrimento, a qual gera tensão e preocupação, afetando o cuidador emocionalmente (Ibiapina, Fernandes, \& Marreiros, 2017; Cardoso et al., 2012). Em outros momentos, as falas revelam a preocupação com o adoecimento.

A gente fica mais preocupado, e com isso pode piorar a nossa saúde. (C16, pai) 
Ficou mais pesado, né, pra mim, mais preocupado, mais ansioso por ela estar daquele jeito. (C9, esposo)

Alguma coisa altera um pouquinho, porque antes a gente não sofria, agora tenho um nervoso [estresse] que a gente não tinha; tem hora que fica ruim. (C17, avó)

Se eu for ficar preocupado demais, eu vou ficar doente, e dessa forma não tenho como eu cuidar dela. (C8, esposo) Tenho que cuidar, se não a gente fica doente. A saúde da gente muda [altera]. Nesse tempo que tenho cuidado dele, às vezes, tenho que tomar até calmante. (C12, esposa)

Para esses cuidadores, a responsabilidade em cuidar está acima de qualquer coisa. Contudo, quando a doença mental afeta um membro da família, a vida passa a ser vista a partir de outro enfoque, dando novos significados aos valores constituídos até então (Ibiapina et al., 2017). Nesse sentido, momentos de frustração e de tensão são intercalados com demonstrações de cuidado e de afeto, mantendo, na medida do possível, certo grau de harmonia. Em meio a essa ambivalência, muitos cuidadores justificam o seu papel por acreditarem que foram escolhidos para cumprir essa tarefa, estando ou não satisfeitos.

\section{O cuidado como predestinação e obrigação do cuidador}

Nessa categoria, buscou-se analisar a compreensão dos participantes sobre sua tomada de decisão ou aceitação em assumir o papel de cuidador, tendo como ponto de partida a seguinte indagação: o que o levou a se tornar o cuidador do seu familiar? Foi possível observar que a função de cuidar de um ente em sofrimento mental é percebida sob várias perspectivas pelo cuidador, vista como predestinação, obrigação e por questão de gênero.

Para alguns dos participantes, o cuidado é percebido como predestinação, como um “castigo divino", ou seja, o fato de ter na família um membro em sofrimento mental está associado à vontade de Deus. É o sacrifício que deve ser feito durante a sua existência, de outra forma é como se o cuidado fosse predestinado a esses cuidadores.

É uma cruz que eu carrego. (C14, irmã) Isso aí é uma cruz que a pessoa tem que carregar. Se a minha cruz é cuidar dele, então é nós mesmo, entendeu? É uma cruz que tem que carregar, né, eu tenho uma, você tem outra, outra pessoa tem outra. Então, se essa caiu pra mim, eu tenho que carregar, alegre ou triste, eu tenho que carregar. A gente tem que cuidar até [silêncio]. Fico pensando: "Meu Deus, me ajude a carregar a minha cruz!" (C7, mãe)

O acolhimento e o vínculo estabelecido representaram o enaltecer do valor da pessoa humana, reafirmando a dignidade e, assim, ambos reinventam outros sentidos e outras possibilidades (Dutra \& Rocha, 2011). Desse modo, a predestinação de ser cuidador como um componente marcante na determinação da qualidade de vida dos cuidadores está relacionada a uma conotação religiosa de humildade, obediência e conformismo (Souza et al., 2011), expressada por meio da aceitação da nova função:“É minha cruz. Tenho que carregar.” (C6, 
filha).

Por outro lado, a religiosidade serve de apoio a esses familiares, pois mediante a crença em Deus eles acreditam que tudo vai passar, e com fé a vida ficará melhor. Para esses cuidadores, a fé é percebida como a única força capaz de aliviar o sofrimento nesse momento de suas vidas. Nesse caso, a religiosidade é tida como um recurso informal e complementar ao serviço público em saúde mental estabelecido pelo Sistema Único de Saúde (SUS) e à rede de atenção em saúde mental (Vecchia \& Martins, 2006). Estudo realizado por Silva, Dimenstein e Leite (2013) apontou o uso de recursos religiosos, entre outros, no cuidado à pessoa em sofrimento mental.

Outro aspecto a ser considerado e que também está ligado à aceitação da nova atividade é o entendimento de que ser cuidador é sua obrigação e/ou que o papel de cuidador não é uma escolha pessoal, mas, sim, imposto pela família ou pela vida. Assim, as experiências novas vividas no cotidiano, sejam elas positivas, sejam negativas, relacionadas ao processo de cuidado, são vistas como uma obrigação pelo cuidador, em razão dos vínculos familiares ou por questões sociais e culturalmente construídas ao longo do tempo.

Tal constatação fica evidente nas falas dos cuidadores a seguir.

Eu tenho que cuidar, essa é minha responsabilidade. (C20, irmã)

Eu tenho que cuidar; nossos pais já morreram faz muito tempo. Eu tenho que cuidar dele até quando Deus quiser. (C14, irmã)

Tenho que fazer comida e cuidar dele. Não pode deixar ele sair sozinho; quando sai fico com medo e preocupada. (C17, avó)

Nota-se na fala dessa avó cuidadora que, ao assumir a responsabilidade pelo cuidado do seu neto em sofrimento mental, sua vida é afetada pela sobrecarga relativa ao acúmulo de tarefas advindas dos cuidados, muitas vezes, abdicando de sua vida para cuidar do familiar em sofrimento (Kebbe et al., 2014). Assim, o cuidado assume características assistenciais de cuidados com higiene, aparência pessoal, orientação, estimulação, escuta, alimentação, lazer, supervisão da administração dos medicamentos e outros que vão além do âmbito da saúde mental, mas, sobretudo, da obrigação de um cuidado de ordem geracional.

Diversos fatores se articulam no momento de "escolher" quem assumirá o papel de cuidador principal do familiar em sofrimento mental. No entanto, na maioria das vezes, é uma mulher da família que assume essa função. Essa particularidade diz respeito à questão do cuidado, cuja função foi historicamente delegada às mulheres (Andrade, 2014). A predominância neste estudo de mulheres cuidadoras corrobora essa afirmativa. Os discursos revelam que os participantes entendem o cuidado como uma função naturalmente atribuída à mulher: "Meu irmão não pode cuidar dela, meu pai não liga muito, ele acha que eu cuido melhor, não sei se é pra se livrar da responsabilidade. Então, vou vivendo assim, é isso" (C6, filha).

O relato dessa filha mostra que a presença feminina no papel de cuidadora principal está ligada a uma série de questões socioculturais que incorporam a mulher ao papel de principal provedora de cuidados à família e aos necessitados, sendo vista como a "melhor 
pessoa" responsável pelo ato de cuidar do familiar. Essa tarefa, muitas vezes, é cumprida com dedicação integral, derivada de uma construção social ideologicamente determinada e aceita, constituindo-se como uma verdadeira obrigação moral, acarretando, muitas vezes, uma sobrecarga física e emocional (Cardoso et al., 2012). "É muito difícil; o homem não sabe lidar muito com essa coisa de dar banho, comida, remédio. É complicado. Acho que isso tem me levado a adoecer, mas tenho que cuidar; é meu pai" (C10, filha).

É importante, também, ressaltar a forte relação hierárquica que existe entre o cuidador e o familiar em sofrimento. Nesse sentido, pode-se observar que, além de perceber o cuidado como atividade naturalizada à figura feminina, a questão de gênero aqui apresentada na fala dessa filha se articula com outras categorias, como geração e hierarquia (Andrade, 2014), estabelecendo as diferenças e os lugares que a mulher deve ocupar na família.

\section{Abdicação da vida social e profissional em prol do cuidado}

A presente categoria foi construída a partir das entrevistas que tinham por objetivo identificar as principais mudanças ocorridas na vida do familiar cuidador.

A generalizada ruptura das relações sociais, decorrente das atividades cotidianas do cuidador, aparece em quase todas as falas como fator indissociável, ao lado da sobrecarga e do processo de adoecimento do cuidador. A ausência de lazer, aliada ao confinamento no ambiente do cuidar constante, leva o cuidador familiar, muitas vezes, a sentir-se sobrecarregado emocionalmente. Ao fazer o seguinte questionamento: "quais as principais mudanças que ocorreram em sua vida após se tornar o cuidador principal?" Obtiveram-se as seguintes respostas:

Fico mais preocupada. Antes saía, viajava [...] hoje fico muito preocupada e não consigo sair mesmo. (C2, mãe)

Fiquei mais sensível, pois agora não trabalho mais; antes me distraía no trabalho. (C4, mãe)

Eu e meu marido íamos ao mercado juntos, e agora não dá, porque tenho que ficar com ela. Também não tenho mais o emprego... (C15, filha)

O trabalho como atividade social é considerado como elemento central na constituição do sujeito. De acordo com Vygotsky (2007, p. 58), “A internalização das atividades socialmente enraizadas e historicamente desenvolvidas constitui o aspecto característico da psicologia humana”. Por meio do trabalho, o ser humano, como sujeito e organismo, interage e se relaciona com o mundo. A abdicação da vida profissional em prol do cuidado tem sido apontada em vários estudos como um dos principais fatores que afetam negativamente a vida do cuidador (Batista, 2015; Oliveira et al., 2013; Sant'Ana et al., 2011).

Tal constatação é um sinal de alerta para a prevenção de possíveis manifestações de sintomas de doenças relacionadas à atividade de cuidador. Em outras palavras, as transformações qualitativas na qualidade da vida social do cuidador no decorrer da atividade do cuidar são importantes para a análise do processo do seu adoecimento, uma vez que são variáveis fundamentais nas estratégias de cuidado da saúde 
de quem cuida. Além disso, a preservação, mesmo que parcialmente, da vida social ativa potencializa o cuidador para exercer sua atividade. Para Silva et al. (2013), ao se articular com vizinhos, amigos, comunidades, parentes próximos ou distantes, o cuidador enriquece suas conexões sociais e opera de forma mais potente em termos de cuidado ao ente em sofrimento mental.

A ausência dessas conexões é percebida nos trechos a seguir:

Fiquei mais nervosa do que antes por cuidar da mãe; me sinto presa por cuidar dela, não consigo sair. Se eu ficar muito tempo longe, a mãe já vai atrás. (C1, filha) Às vezes fico sem dormir, amanheço cansada pra ir trabalhar. Também quero sair de casa para passear e não posso, pois tenho que ficar cuidando dela; isso é ruim pra mim. Sou uma moça solteira, e não posso viver minha vida, mas fazer o quê? (C6, filha)

Eu não tenho tempo pra me cuidar, eu fico muito preocupada de cuidar dele, porque tudo o que eu faço para ele, tudo que eu faço, eu agrado; faço tudo, aí depois ele se revolta contra mim, fala que eu não faço nada pra ele. (C18, mãe)

Eu não saio mais de casa, pois chamo ela para sair ela não que ir; aí eu não tenho como sair e deixar ela sozinha. (C9, esposo)

Observa-se nessas falas que os informantes não se sentem motivados a restabelecer o convívio social. A dedicação ao exercício do cuidado acarreta na vida desses cuidadores: falta de autonomia para conduzir a própria vida, impossibilidade de sair de casa, preocupação e limitação da vida social, além de sentimentos de solidão e perda de liberdade. $\mathrm{O}$ isolamento social pode estar associado a vários fatores, como a falta de apoio familiar ou insegurança em deixar o familiar sozinho ou com outra pessoa. Nesse sentido, é necessário esclarecer o cuidador da pessoa em sofrimento mental acerca das questões que vêm junto com o adoecimento (Silva et al., 2013), para que ele compreenda a importância da construção de redes sociais no apoio ao cuidado.

Ah, menina, tinha vez que eu me desesperava muito. Comecei a cuidar da mais velha [outra filha] com depressão, também sofri muito. Nossa, quando ela deu uma equilibrada [melhorada], veio esse aí [filho com esquizofrenia]. Esse aí deu trabalho, hein! Nossa! Foi muito difícil pra poder estar do jeito que ele está agora. [...]. Aí eu sofri muito. Tinha dia que eu pensava que não ia dar conta. Então, mas agora graças a Deus, que está acompanhando com o psiquiatra que ele [o filho] deu uma controlada mais ou menos. [...] tinha dia que eu chorava, tinha dia que eu estava lá na beira do fogão fazendo comida ninguém notava, era chorando por vida [...], mas sempre pedindo força pra Deus para vencer [...] aí graças a Deus, no ponto que ele está agora não sofro muito mais; tenho que acompanhar ele. (C18, mãe)

Pode-se considerar que tais falas evidenciam a urgência de intervenção no grupo familiar para que o procedimento de apoio psicossocial, por meio de políticas públicas em saúde mental, aponte para a efetivação de apoio à 
família cuidadora, garantindo subsídios (econômicos, culturais, pedagógicos e instrumentais) para lidar no cotidiano com o familiar em sofrimento mental. Gomes e Santos (2016) explicam que é preciso estar atento às expressões evidenciadas nas falas dos cuidadores, sejam elas exteriorizadas de forma negativa, sejam nas falas que indicam positividade, pois suas lamentações diante das circunstâncias vividas refletem suas dificuldades. Essas informações revelam a necessidade de construção de estratégias mais eficientes de suporte ou apoio à família (Silva et al., 2013), sobretudo ao cuidador principal, que, por vezes, poderá adoecer em decorrência dessa função (Olegário et al., 2012).

\section{Considerações finais}

Considerando as mudanças de paradigmas na assistência à pessoa em sofrimento mental, as quais atribuíram à família o papel principal no processo de reabilitação social e na manutenção do cuidado ao familiar em sofrimento mental, nesta pesquisa buscou-se compreender como o cuidador principal percebe o cuidado como um processo que leva ao seu adoecimento ao longo do tempo.

Os dados obtidos neste estudo corroboram os conhecimentos já produzidos sobre o tema, apontando a permanência da figura feminina associada ao cuidado à pessoa em sofrimento mental. A predominância da mulher, entre os participantes da pesquisa, como cuidadora principal, evidencia que a sociedade ainda não superou a construção social de gênero que atribui à mulher responsabilidade pelo cuidado, independentemente da hierarquia de geração, da vida profissional e/ou, até mesmo, da sua condição de saúde.
Este estudo destacou o impacto negativo na saúde do cuidador principal ao assumir sozinho a responsabilidade pelo cuidado domiciliar do familiar doente. Pode-se perceber, a partir dos depoimentos dos participantes, como a ausência de apoio de outros membros da família contribui para a sobrecarga nessa atividade e, consequentemente, para o adoecimento do cuidador. A ausência de vida social e profissional também foi relatada pelos cuidadores. Nesse sentido, destaca-se a necessidade de apoio social como uma ação importante para a prevenção, a promoção e o restabelecimento da saúde do cuidador.

As informações obtidas evidenciaram que, mesmo reconhecendo o cuidado como fator inerente ao adoecimento, muitos cuidadores consideram essa atividade como predestinação, ou seja, ligada à vontade de Deus, ou, ainda, o cuidado como uma obrigação. Uma vez que existe um vínculo consanguíneo entre cuidador e sujeito em sofrimento mental, a responsabilidade dessa atividade é assumida sem questionar a forma como lhe foi imposta.

Por fim, o estudo aponta para a necessidade de programas e estratégias de assistência por parte da equipe de saúde mental que orientem a família quanto à reorganização de papéis e responsabilidades de cada membro diante da atividade de cuidado, diminuindo, assim, a sobrecarga e possível adoecimento do cuidador principal. É preciso que haja estabelecimento de vínculo e de responsabilização de todos os atores envolvidos na rede de cuidados, no sentido de produzir novos olhares para o papel desempenhado pelo cuidador principal. 


\section{Referências}

Aguiar, W. M. J. (2015). A pesquisa em Psicologia sócio-histórica: contribuições para o debate metodológico. In A. M. B. Bock, M. G. M. Gonçalves \& O. Furtado (Ed.). Psicologia sócio-bistórica: uma perspectiva crítica em Psicologia (pp. 157-171. São Paulo: Cortez.

Almeida, M. D. C. L. (2015) Desinstitucionalização do tratamento psiquiátrico e gênero: o impacto causado na vida do cuidador do portador de transtorno mental. Estudos de Sociologia, 2(21), 345-363. Recuperado em 12 novembro, 2018, de https://periodicos.ufpe.br/revistas/revso cio/article/view/235660.

Andrade, A. P. M. (2014). (Entre)laçamentos possíveis entre gênero e saúde mental. In V. Zanello \& A. P. M. Andrade. Saúde mental e gênero: diálogos, práticas e interdisciplinaridade (pp. 59-77). Curitiba: Appris.

Bardin, L. (2011). Análise de conteúdo. Lisboa: Edições.

Batista, E. C. (2015). A saúde mental do cônjuge cuidador familiar da parceira em sofrimento psíquico grave. Dissertação de mestrado em Psicologia, Fundação Universidade Federal de Rondônia, Rondônia. Recuperado em 13 novembro, 2018, de http://www.ri.unir.br/jspui/handle/1234 $56789 / 1195$.

Batista, E. C., Ferreira, D. F., \& da Silva Batista, L. K. (2018). O papel do cuidador familiar no campo da saúde mental: avanços e contradições. Clinica \& Cultura, 6(1), 21-30. Recuperado em 12 novembro, 2018, de https://seer.ufs.br/index.php/clinicaecult ura/article/view/5743/7259.

Batista, E, C., Silva, J. C. B., Ferreira, D. F., \& Batista, L. K. S. A saúde mental e o cuidado à pessoa em sofrimento psíquico: avanços, rupturas e desafios na história da loucura. In E. C. Batista \& Z. G. Souza Neto (Ed.). Interdisciplinaridade em Psicologia na Amazônia: saúde, educação e sociedade (pp. 15-37). Curitiba: CRV.

Bock, A. M. B. (2015). Psicologia sócio-histórica: uma perspectiva crítica em Psicologia. São Paulo: Cortez.

Boff, L. (2014). Saber cuidar: Ética do bumano Compaixão pela terra. Petrópolis: Vozes.

Cabral, B. P. D. A. L., \& Nunes, C. M. P. (2015). Percepções do cuidador familiar sobre o cuidado prestado ao idoso hospitalizado. Revista de Terapia Ocupacional da Universidade de São Paulo, 26(1), 118-127. Recuperado em 18 novembro, 2018, de https://doi.org/10.11606/issn.22386149.v26i1p118-127.

Cardoso, L., Galera, S. A. F., \& Vieira, M. V. (2012). O cuidador e a sobrecarga do cuidado à saúde de pacientes egressos de internação psiquiátrica. Acta Paul Enferm, 25(4), 517-23. Recuperado em 17 novembro, 2018, de http://www.scielo.br/pdf/ape/v25n4/06. pdf. Cardoso, L., \& Galera, S. A. F. (2011). O cuidado em saúde mental na atualidade. Revista da Escola de Enfermagem da USP, 45(3), 687-691. Recuperado em 14 novembro, 2018 , de http://dx.doi.org/10.1590/S008062342011000300020 .

Cardoso, L., Vieira, M. V., Ricci, M. A. M., \& Mazza, R. S. (2012). Perspectivas atuais sobre a sobrecarga do cuidador em saúde 
mental. Revista da Escola de Enfermagem da USP, 46(2), 513-517. Recuperado em 13 novembro, 2018, de http://dx.doi.org/10.1590/S008062342012000200033.

Coelho, R. S., Velôso, T. M. G., \& Barros, S. M. M. (2017). Oficinas com usuários de saúde mental: a família como tema de reflexão. Psicologia: Ciência e Profissão, 37(2), 489-499. Recuperado em 12 novembro, 2018, de http://dx.doi.org/10.1590/19823703002612015.

Costa, J. P., Jorge, M. S. B., de Lima Coutinho, M. P., Costa, E. C., \& Holanda, Í. T. A. (2016). A reforma psiquiátrica e seus desdobramentos: representações sociais dos profissionais e usuários da atenção psicossocial. Psicologia e Saber Social, 5(1), 35-45. Recuperado em 15 novembro, 2018, de 10.12957/psi.saber.soc.2016.15855.

Covelo, B. S. R., \& Badaró-Moreira, M. I. (2015). Laços entre família e serviços de saúde mental: a participação dos familiares no cuidado do sofrimento psíquico. Interface: Comunicaşão, 19(55), 1133-1144. Recuperado em 16 novembro, 2018, de http://dx.doi.org/10.1590/180757622014.0472 .

Delalibera, M., Presa, J., Barbosa, A., \& Leal, I. (2015). Sobrecarga no cuidar e suas repercussões nos cuidadores de pacientes em fim de vida: revisão sistemática da literatura. Ciência \& Saúde Coletiva, 20(9), 2731-2747. Recuperado em 17 novembro, 2018, de http://dx.doi.org/10.1590/141381232015209.09562014.
Delgado, P. G. (2014). Sobrecarga do cuidado, solidariedade e estratégia de lida na experiência de familiares de Centros de Atenção Psicossocial. Physis: Revista de Saúde Coletiva, 24(4). Recuperado em 14 novembro, 2018, de http://www.scielo.br/pdf/physis/v24n4/ 0103-7331-physis-24-04-01103.pdf.

Dutra, V. F. D., \& Rocha, R. M. (2011). O processo de desinstitucionalização psiquiátrica: subsídios para o cuidado integral. Revista de Enfermagem, 19(3), 386391. Recuperado em 12 novembro, 2018, de

http://www.facenf.uerj.br/v19n3/v19n3a 08.pdf.

Fonseca, N. D. R., Penna, A. F. G., \& Soares, M. P. G. (2008). Ser cuidador familiar: um estudo sobre as consequências de assumir este papel. Physis, 18(4), 727-743. Recuperado em 10 novembro, 2018, de http://dx.doi.org/10.1590/S010373312008000400007.

Freitas, M. T. D. A. (2002). A abordagem sóciohistórica como orientadora da pesquisa qualitativa. Cadernos de pesquisa, (116), 2139. Recuperado em 11 novembro, 2018, de http://dx.doi.org/10.1590/S010015742002000200002.

Gomes, T. B., \& Santos, J. B. F. D. (2016). Dilemas e vicissitudes de famílias em situação de vulnerabilidade social no contexto da desinstitucionalização psiquiátrica. Physis: Revista de Saúde Coletiva, 26(1), 271-287. Recuperado em 13 novembro, 2018, de http://dx.doi.org/10.1590/S0103-

73312016000100015. 
Gomes, M. L. P., Silva, J. C. B. D., \& Batista, E. C. (2018). Escutando quem cuida: quando o cuidado afeta a saúde do cuidador em saúde mental. Revista Psicologia e Saúde, 10(1), 3-7. Recuperado em 12 novembro, 2018, de http://dx.doi.org/10.20435/pssa.v10i1.530.

Goulart, M. S. B., Silva, C. R., \& Silva, E. R. D. (2015). A universidade e a reforma psiquiátrica: fios e desafios. Pesquisas e Práticas Psicossociais, 10(2), 368-381. Recuperado em 12 novembro, 2018, de http://pepsic.bvsalud.org/pdf/ppp/v10n 2/13.pdf.

Ibiapina, A. R. S., Fernandes, M. A., \& Marreiros, G. A. (2017). As multifaces da desinstitucionalização psiquiátrica: percepção dos familiares. Revista Interdisciplinar, 9(4), 105-113. Recuperado em 12 novembro, 2018, de https://revistainterdisciplinar.uninovafapi. edu.br/index.php/revinter/article/view/ 947.

Kebbe, L. M., Rôse, L. B. R., Fiorati, R. C., \& Carretta, R. Y. D. (2014). Cuidando do familiar com transtorno mental: desafios percebidos pelos cuidadores sobre as tarefas de cuidar. Saúde em Debate, 38(102), 494-505. Recuperado em 14 novembro, 2018, de http://dx.doi.org/10.5935/01031104.20140046.

Nascimento, K. C. D., Kolhs, M., Mella, S., Berra, E., Olschowsky, A., \& Guimarães, A. N. (2016). O desafio familiar no cuidado às pessoas acometidas por transtorno mental. Revista de Enfermagem UFPE, 10(3), 940948. Recuperado em 14 novembro, 2018, de

https://www.lume.ufrgs.br/bitstream/ha ndle/10183/141077/000990845.pdf?sequ ence $=1$.

Olegário, B. B., Beuter, M., Girardon-Perlini, N. M. O., Brondani, C. M., Budó, M. D. L. D., \& dos Santos, N. O. (2012). A sobrecarga do familiar cuidador no âmbito domiciliar: uma revisão integrativa da literatura. Revista Gaúcha de Enfermagem, 33(1), 147-156. Recuperado em 14 novembro, 2018, de http://dx.doi.org/10.1590/S198314472012000100020.

Oliveira, L. V. D., Cirilo, L. S., \& Costa, G. M. C. (2013). O cuidar do portador de transtorno mental: significado para a família. Revista Baiana de Saúde Pública, 37(1), 164.

Sant'Ana, M. M., Pereira, V. P., Borenstein, M. S., \& Silva, A. L. D. (2011). O significado de ser familiar cuidador do portador de transtorno mental. Texto \& contexto enferm, 20(1), 50-58. Recuperado em 14 novembro, 2018, de http://www.scielo.br/pdf/tce/v20n1/06. pdf.

Silva, V. H. F. D., Dimenstein, M., \& Leite, J. F. (2013). O cuidado em saúde mental em zonas rurais. Mental, 10(19), 267-285. Recuperado em 14 novembro, 2018, de http://pepsic.bvsalud.org/pdf/mental/v1 0n19/a08v10n19.pdf.

Souza, R. C., Caldas, N. M, Pinto, D. M. R., \& Soares, V. R. (2011). Avaliação da qualidade de vida de cuidadores de sujeitos em sofrimento psíquico. UDESC em Ação, 5(1). Recuperado em 11 novembro, 2018, de

http://www.revistas.udesc.br/index.php/ cidadaniaemacao/article/download/2235 /pdf_83. 
Vicente, J. B., Mariano, P. P., Buriola, A. A., Paiano, M., Waidman, M. A. P., \& Marcon, S. S. (2013). Aceitação da pessoa com transtorno mental na perspectiva dos familiares. Revista Gaúcha de Enfermagem, 34(2), 54-61. Recuperado em 10 novembro, 2018, de http://dx.doi.org/10.1590/S198314472013000200007.

Dalla Vecchia, M., \& Martins, S. T. F. (2006). O cuidado de pessoas com transtornos mentais no cotidiano de seus familiares: investigando o papel da internação psiquiátrica. Estudos de Psicologia (Natal), 11(2), 159-168. Recuperado em 15 novembro, 2018, de http://dx.doi.org/10.1590/S1413294X2006000200005.

Vygotsky, L. S. (2008). Pensamento e linguagem. São Paulo: Martins Fontes.

Vygotsky, L. S. (2004). Teoria e método em Psicologia. São Paulo: Martins Fontes.

Vygotsky, L. S. (2007). A formação social da mente: 0 desenvolvimento dos processos psicológicos superiores. São Paulo: Martins Fontes.

Recebido em: 30/8/2017 Aprovado em: 25/11/2018 